\title{
A interação em estudo: as análises das correntes teóricas sobre o conceito de design de interação para profissionais e educadores
}

Eduardo Ariel de Souza Teixeira (ESPM, Brasil)

eariel@espm.br

Rua do Rosário, 90, Centro

Rio de Janeiro, RJ, Brasil CEP: 20041-002 


\title{
A interação em estudo: as análises das correntes teóricas sobre o conceito de design de interação para profissionais e educadores
}

Resumo: O artigo faz uma breve revisão da literatura e, em seguida, realiza entrevistas com profissionais e educadores com o intuito de verificar o entendimento deles sobre os conceitos pesquisados. Assim, deseja-se obter as impressões mais atuais sobre o "Design de Interação" e a "Arquitetura de Informação".

Palavras-chave: Design de interação, arquitetura de informação, experiência de uso.

Interaction study: the analysis of current theory on the concept of interaction design for professionals and educators

\begin{abstract}
The article is a brief review of the literature and then conducts interviews with professionals and educators in order to verify their understanding of the concepts studied. Therefore, it is desirable to get the most current impressions on "Interaction Design" and "Information Architecture".
\end{abstract}

Key words: Interaction Design, Information Architecture, user experience. 


\section{Introdução}

A pesquisa de natureza essencialmente teórica, mas com uma perspectiva de que os resultados tenham uma aplicação prática, contém ainda também uma parte descritiva, onde o seu objetivo principal é investigar de modo crítico o conceito de "Design de Interação" e seu entendimento mais contemporâneo.

Com isso, busca-se através da revisão bibliográfica e de entrevistas estruturadas com profissionais tornar mais preciso o entendimento sobre as novas vertentes que norteiam o conceito de interação, a fim de identificar questões teóricas e empíricas centrais ao tema proposto. Ademais, as tendências, os aspectos e as manifestações mais recentes dessa área para o profissionais relacionados com a "Arquitetura de Informação" e o "Design de Interfaces".

\section{Design de Interação}

Há aqui, logo no início, uma série de questionamentos que talvez passem sempre pelo mesmo caminho - a busca do entendimento de Design de Interação. Assim, uma das metas está no levantamento do referencial teórico contido aqui e como pode auxiliar na convergência no "plano das ideias" para que se possa estabelecer um diálogo sobre o projeto interativo de qualquer TIC. Assim sendo, ao longo deste capítulo, há uma série de pontos de conexão entre o Design de Interação e a Comunicação. Para facilitar o entendimento, para o autor, a Comunicação é, ao menos em parte, uma interface tecnológica da relação usuário-interação-informação, sendo em si um elemento fundamental para o estabelecimento do processo comunicacional em espaços digitais, seja entre pessoas-pessoas ou sistemas-pessoas. Desse modo, fundamentalmente por ele, a interação, seja conceitual, possível e percebida, é o instrumento-chave, uma vez que o Design, como atividade projetual, serve para moldar a interface, atuando sobre os estilos de interação e podendo, em alguns casos, moldar o universo, contexto macro em que ocorre a interação do usuário com a interface da TIC, seja em conjunto com estratégias e ações de comunicação, reforçando a importância do conteúdo como "Genoma primordial", seja tipificando em valor os aspectos culturais envolvidos nessa rede e, sobretudo, apagando os limites da forma e da função que delimitam as fronteiras dessas três áreas de conhecimento (Comunicação, Ciência da Informação e Design).

Agora, de maneira inicial, cabe fazer uma reflexão sobre o ritmo com que os usuários têm de se adaptar às novas tics. Para tanto, concorda-se com Robinson (2004) quando ele comenta que a tecnologia moderna está avançando de modo tão veloz que a maior parte dos consumidores está ficando 
confusa e frustrada. Já para Preece, Rogers e Sharp (2002), muitos produtos que requerem a interação dos usuários para a realização de suas tarefas, por exemplo, comprar um ingresso pela Internet, fotocopiar um artigo, gravar um programa de TV, não foram necessariamente projetados tendo o usuário em mente; foram tipicamente projetados como sistemas para realizar determinadas funções. Pode ser que funcionem de maneira eficaz, olhando-se da perspectiva da engenharia, mas geralmente os usuários do mundo real é que são sacrificados. Nesse momento, pode-se dizer que a experiência pode não ser agradável. Talvez possa ser irritante, frustrante etc. Com isso, surge uma pista sobre como as emoções, durante a interação, podem afetar as pessoas durante a tentativa de uso do produto ou de uma TIC.

O objetivo do Design, em especial aquele que preveja a interação ou tido como "Design de Interação", consiste em redirecionar essa preocupação, trazendo a usabilidade para dentro do processo de projetação. Já para Preece, Rogers \& Sharp (2002), o design de interação compreende uma dimensão mais contextual, podendo mudar em função do local e da tarefa, conforme explicitado abaixo:

"Design de produtos interativos que fornecem suporte às atividades das pessoas, seja no lar ou no trabalho".

Por conta disso, Saffer (2007) considera que o design de interação está mais relacionado com o comportamento humano do que com a aparência da tela ou as funções escondidas de uma interface. Enquanto Winograd (1997, apud Preece, Rogers \& Sharp, 2002), descreve o design de interação como "o projeto de espaços de comunicação e interação humana". Nesse sentido, o design de interação consiste em encontrar maneiras de fornecer suporte às pessoas e as suas atividades cotidianas através de uma interface que tenha um entendimento imediato, além de um estilo de interação quase natural e espontâneo. Sendo assim, essas definições de forma geral postulam que, em primeiro lugar, vêm os objetivos dos usuários, e, por último, a ferramenta (sistema, interface, tela, botão).

De acordo com Preece, Rogers \& Sharp (2002), ao perceberem que as novas tecnologias estão oferecendo maiores oportunidades para fornecer suporte às pessoas em seu dia-a-dia, pesquisadores e profissionais foram levados a considerar outras metas. A emergência de tecnologias (p. ex.: realidade virtual, Web, computação móvel, interação touch screen) inseridas em uma diversidade de áreas de aplicação (p. ex.: entretenimento, educação, residências, áreas públicas) trouxe à tona um conjunto maior de interesses. Além de enfocar principalmente a melhoria da eficiência e da produtividade 
no trabalho, o design de interação está cada vez mais preocupado com o lúdico como agente incentivador da exploração. Sendo assim, na teoria as interfaces dos sistemas e produtos deveriam ser:
1. satisfatórias;
2. agradáveis;
3. divertidas;
4. interessantes;
5. úteis;
6. motivadoras;
7. esteticamente apreciáveis;
8. incentivadoras de criatividade;
9. compensadoras;
10. emocionalmente adequadas às tarefas dos usuários.

Em suma, o objetivo de desenvolver produtos interativos agradáveis, divertidos, esteticamente apreciáveis está principalmente na experiência que estes produtos proporcionarão ao usuário, isto é, como ele se sentirá na interação com o sistema. Isso envolve explicar a natureza da experiência do usuário em termos subjetivos. Ademais, concordando com Saffer (2007), o design de interação deveria ter como meta conectar pessoas através dos produtos, sendo um espaço informacional onde a comunicação pode ocorrer. Desse modo, pode-se assumir também que os produtos são uma interface para unir pessoas, sendo o meio desta comunicação e não o seu fim. Sendo assim, todo o projeto de interação de qualquer interface deveria estar fundamentado nas necessidades, na tarefa, na cultura de seus usuários finais. Logo, o planejamento das ações deveria ser centrado no usuário, assim como todo o projeto.

\section{Arquitetura de Informação}

Neste tópico, enfoca-se a lógica de que o valor está na informação oriunda da experiência, só que agora mediado por uma disciplina conhecida como Arquitetura da Informação (AI), na qual qualquer forma endógena, unidirecional e linear de criar, pensar, produzir e consumir perde espaço. No entanto, a estrutura, a busca e a recuperação da informação ganham relevância. Mesmo assim, como todo o produto digital, em um ambiente relacional e comunicacional, pode-se buscar um entendimento onde "o processo de difusão é, portanto, um processo criador, pois é em seu interior que se define o objeto técnico inovante (CORSANI, 2003)". De maneira correlata as TICs intensificaram e 
ampliaram as possibilidades de fazer circular, cooperar, interagir, usar/consumir. O estatuto de uso das "coisas" não é de propriedade da fábrica, é da trama social, dos usuários e de seu grupo de referência. A natureza do trabalho, o processo de inovação e a incorporação de conhecimentos tomam formas difusas, contínuas, nas quais o interno e o externo se conectam. As estratégias de comunicação das empresas mais competitivas trilham caminhos que levam em consideração: (1) a pulverização, instantaneidade e onipresenças das novas mídias; (2) a demanda por um relacionamento interativo, em tempo real e polifônico; (3) a capacidade de o consumidor se posicionar e disseminar seu ponto de vista sobre produtos, marcas, organizações e ideias; (4) o potencial transformador das Tics sobre a produção e as relações sociais e (5) o interesse do consumidor em ser reconhecido, diferenciado, sem que haja a perda da percepção de privacidade. Sendo assim, tem-se visto a redução gradativa da participação das mídias massivas tradicionais no composto de comunicação e uma emergência gradativa de ações alternativas, digitais, de experiência (no ponto de venda ou em eventos proprietários), interativas, transmidiáticas. Em todas elas, a relevância do conteúdo, a inovação e a função entretenimento da comunicação são elementos distintivos, ainda mais quando se entende que a base está na arquitetura da Infovia, em especial da própria informação como agente transformador dos usuários e gerador de novas demandas. Ou seja, o valor não está nas coisas em si, mas nos conhecimentos ali contidos e nos novos saberes criados com seu uso. A informação sobre algo pode valer tanto ou mais que o objeto em si. Para tal, a AI traz contribuições bem efetivas para esta discussão, pois, segundo Fox (2001), enquanto conceito, ela precisa ser considerada sob uma perspectiva ecológica que envolva o conteúdo, a estratégia de negócio e o usuário.

De maneira mais específica recorre-se para um autor com uma proposição mais instrumental. Assim, Fox (2001) propõe e destaca de maneira conjunta, que a Arquitetura de Informação é a ciência de estruturar e organizar sistemas de informação para auxiliar as pessoas a alcançarem seus objetivos. Já Rosenfeld e Morville (1998) relacionam a AI à biblioteconomia. Consideram, inclusive, que os bibliotecários e os profissionais da ciência de informação sejam as pessoas mais capacitadas para atuar nesta área, visto que esta envolve a estruturação e organização de informação para os quais se utilizam os conceitos oriundos da Ciência da informação. Contudo, Garrett (2003), amplia este campo ao acreditar que a Arquitetura da Informação diz respeito ao desenvolvimento do conteúdo e à estruturação da experiência do usuário. E defende que, por lidar com conteúdo, este campo envolve também uma série de disciplinas que historicamente dizem respeito à organização, grupamento, ordem e apresentação do mesmo, tais como: Jornalismo, Publicidade/Propaganda e 
outras. Para ele, a Arquitetura da Informação (AI) está relacionada com criação de esquemas organizacionais e de navegação, que ajudam os usuários a se moverem através do conteúdo do site, de forma eficiente e efetiva.

Decerto muitas das definições de Arquitetura de Informação passam pela elaboração de um sistema que apoie aos usuários no processo de busca de informação, mas ela vai muito além do instrumental e tem relação direta com a visão estratégica. Isto ocorre, pois demanda um profundo entendimento do negócio da empresa, seu mercado, clientes, concorrentes, estratégia e aspectos culturais e políticos. Também passa por uma investigação detalhada das necessidades, problemas e expectativas de seus usuários atuais, bem como potenciais. Já para Morrogh (2003), em Information Architecture: An Emerging 21st Century Profession, "o foco da Arquitetura de Informação é o projeto de estruturas (ambientes informacionais) que fornecem aos usuários recursos necessários para transformar suas necessidades em ações e para atingir seus objetivos com sucesso."

Para Morville (2007), não há uma definição específica e sucinta para Arquitetura de Informação, e resume em quatro definições uma abordagem generalista sobre as preocupações do estudo da Arquitetura de Informação. Ainda assim, para ele pode-se relacionar a Arquitetura de Informação com:

- O design estrutural para o compartilhamento de informações com o objetivo de facilitar as tarefas em um ambiente intuitivo.

- A combinação entre sistemas de navegação para Web sites e intranets, rotulagem, e busca.

- A arte e a ciência da modelação da informação de produtos e experiências, oferecendo suporte à boa usabilidade e acessibilidade.

- Uma disciplina emergente e uma comunidade de prática profissional focada em trazer os princípios do design e da arquitetura para o cenário digital.

Para outros pesquisadores o destaque é dado sobre os elementos que definem a estrutura. Com isso, busca-se um entendimento que remeta aos esquemas de produção, de modo mais sequencial, quase limitando o seu entendimento ao nível estritamente da competência e da área de formação. Dentre eles está, Garret (2003) quando propõe um dos mais conhecidos, onde cinco planos projetuais fornecem um quadro conceitual sobre os problemas da experiência do usuário e as áreas relacionados com as questões provenientes da interação. 


\section{As entrevistas}

As entrevistas foram realizadas no segundo semestre de 2012 e contaram com uma lógica pré-definida, logo pode-se dizer que foi um procedimento estruturado, onde os conceitos foram apresentados de modo sequencial e sempre um por vez (exatamente como abaixo).

1. Informação.

2. Interação.

3. Design de Interação.

4. Arquitetura de Informação.

5. Competências relativas com os perfis.

O método foi extremamente rigoroso para garantir que o entrevistado não influenciasse o participante. Por isso, o entrevistado só passava para a próxima folha quando achasse que tivesse terminado de falar sobre o tópico vigente. E, detalhando o procedimento um pouco mais, todos conceitos estavam impressos em folhas separadas, com a mesma tipografia, cor e corpo.

Os colaboradores tinham o perfil comum, ou seja, quase todos lecionavam em cursos de pós-graduação e exerciam uma atividade profissional no mercado - ou tinham feito isso de modo recente.

Nos próximos parágrafos estão os resultados das entrevistas agrupados segundo a ordenação em que conceitos foram apresentados, exatamente como foram organizados no caderno entregue para os colaboradores. De modo geral, as análise respeitam a sequência estabelecida para o procedimento (conteúdo relacionado com cada tópico), em seguida existe o resumo do que foi dito contendo algumas citações feitas pelos colaboradores.

\subsection{Informação}

A primeira palavra, impressa nas folhas entregues para os participantes, trouxe por parte dos entrevistados, ainda modo resumido, observações relativas com: a pluralidade de entendimentos, o domínio humano sobre sua natureza, a ampla quantidade de informações nos tempos atuais e o seu caráter onipresente na sociedade pós - Internet. Além disso, foram postuladas outras relações com a "Necessidade", o "Design" e a "Arquitetura de Informação". Dito isso, os próximos parágrafos trazem (em um sentido lateral) a relação da "Informação" como agente de desenvolvimento do ser humano.

Para iniciar, o entrevistado NMLCAGPU1112 ao pensar em "Informação", contribui para essa discussão parcial, lembrando o pesquisador Peter Morville. Logo depois, seguindo em sua argumentação, elaborando sobre a 
complexidade, assim como os demais colaboradores, até dizer que não é um conceito muito bem definido. Para justificar sua ponderação contextualizou do seguinte modo: “... é um termo polissêmico na visão da Ciência da Informação. Ele teria diversos significados, podendo ser interpretado de várias formas”. Mesmo assim, encontrou uma definição que prefere, lhe traz valor e possui sentido. Por isso, disse: "Eu gosto muito da visão onde a informação é vista por si mesma. Nela se entende a informação como um atributo do universo, ou seja do nosso mundo. E ele tem espaço, energia, massa, movimento e informação". Enquanto a entrevista com o colaborador MMFRFCOP1112 remeteu, logo em seu início, ao que ele entendia como gênese da informação. Para ele a informação está relacionada com dado, mas decerto é aquilo que se consegue construir a partir dele. Na medida que você consegue contextualizar esse dado ele passa a ser uma informação. Após esta argumentação o entrevistado disse: "A informação mais do que qualquer outra coisa é uma função". Assim, ele continuou: "A função de qualquer dado é se tornar informação". Já outro entrevistado fez referencia ao excesso de informação e a sua onipresença na vida moderna. Contudo, ante de seguir nessa linha de raciocínio outro colaborador (com de código DMLMACop1112) verbalizou o seu entendimento, comparando com uma função mais cotidiana, mesmo sem citar terminologias como necessidade de informação ou competência em informação trouxe um prisma micro e talvez bastante próprio, ao dizer: "... diz respeito com solução de problemas ou como aprender a lidar com eles”. Desse modo, agora de volta para a discussão anterior, o entrevistado MMLTPAPM1012 começou a sua resposta dizendo: "A informação é o meio no qual a gente vive". O mesmo colaborador justificou esse seu início de pensamento (ao ir além do contexto), postulando que se vive no meio da informação e, ao mesmo tempo, ela liberta o indivíduo, dando autonomia para que ele (o usuário) fazer o que quiser, mas simultaneamente a "Informação" condiciona as pessoas em diversas situações delimitadoras. Assim, ela remete ao Bill Viola (videoartista estadunidense, nascido em Nova Iorque) quando este remete ao acesso dela, bem como o seu desperdício pela sua superexposição.

Uma outra abordagem surge para o conceito de "Informação" quando o entrevistado MMERFINPU0912 lembrando Richard Saul Wurman reforça a relação do conceito de "Informação" com a disciplina "Arquitetura de Informação". Para ele existe uma relação direta entre ambos. De modo, bem similar, o entrevistado mMEBRgpu1212 ao falar sobre o conceito de "Informação", de início faz relação com a sua profissão e a sua atividade fim (arquiteto de informação). Já o entrevistado 
MFChMGPU1212: "Hoje em dia, você tem informação em qualquer hora e lugar. Acredito que existe um excesso de informação. É um dilema entre a quantidade e o que você recebe com qualidade". Ele ressalta outra característica desse momento ao falar sobre "presença" e "instantaneidade" da informação, destacando que ela pode envolver uma região de modo simultâneo - assim que o fato acontece. Além disso, ao mesmo tempo, ela (Informação) não possui mais fronteiras, sendo transnacional quanto a sua difusão. Em virtude da sua quantidade, retornando ao caso do excesso, ele defende (como projetista) que um dos desafios mais emergentes está em colocar para o usuário a informação que ele precisa naquele momento de necessidade, forma fácil, em virtude da velocidade e da premência. Com isso, ele defende a priorização da informação para o usuário, em dado momento no tempo, segundo o perfil dele - se possível de modo personalizado ou até individualizado (aqui seria um nível mais elaborado). Sendo esta proposição um dos objetivos da empresa em que ele trabalha, tanto que existem reuniões frequentes entre arquitetos de informação para debater o tema em questão. Além disso, a relevância do assunto ganha ainda mais peso quando se tem um dos maiores portais de informação da Internet brasileira como produto principal. Dito isso, ele se questionou duas vezes:

1. "Como se faz para ser preciso na informação, mostrando também conteúdo relacionado sem deixar a interface poluída?”.

2. "Como a gente filtra para mostrar para o usuário de um forma mais fácil?”.

As ponderações das pessoas que participaram da pesquisa denotam sempre a importância do conceito em discussão, mesmo que seja difícil alcançar uma definição formal que seja atual ficam alguma particularidades indicativas, mencionadas no primeiro parágrafo desse tópico, de como alguns projetistas e educadores percebem o conceito de "Informação".

\subsection{Interação}

Os entrevistados compartilharam impressões diversas, porém com eixos norteadores bem similares. Em especial, como a "Interação" tem uma ampla 
dimensão humana e como ela tanto marca como é moldada pelo mesmo plano existencial. Além disso, seja por meio do tempo, da sua forma e acionamentos é que o usuário (ser humano em uma visão mais ampla) exerce o direito criador. Nele, transforma o conceito através do uso, das premissas sociais e, especialmente, do desejo de alcançar o seu destino.

De maneira específica, apresentando o que fora verbalizado, a "Interação" para o educador e profissional (DMLMACOP1112) possui um delimitador temporal. Desse modo, o tempo vigente, a forma como se manifesta, a própria demanda, o meio inerente ao uso, a densidade permitida, os tipos de acionamentos, as respostas fornecidas pelo aparato e a constante mutação em tempo real devem estar contidos em qualquer definição relativa com tal conceito. Pela proliferação de tecnologias interativas o entrevistado acredita que estamos vivendo a era da onipresença da interação tecnológica. Em seguida, ele postulou que os tipos, a densidade e a profundidade da interação pode ser diferente em virtude das características dos dispositivos. Ademais, também destacou que o grau de profundidade ou de intensidade nem sempre é igual, existindo horas em que o usuário investiga mais que outras. Sendo assim, o entrevistado acredita que a tecnologia ainda exerce um papel muito grande na percepção e na busca de qualquer definição mais formal, pois a quebra de paradigma (por meio de um novo produto tecnológico) pode tornar obsoleto a compreensão anterior.

De modo similar, mas com uma abordagem toda própria sobre a questão temporal da "Interação", em sua primeira frase (após uma breve pausa) o entrevistado mMLtPaPM101 disse: "Aquilo que marca nossa passagem pelas coisas”. Nesse ponto, diz respeito com capacidade humana de interagir com objetos ou pessoas. Ele segue refletindo com: “..é o relacional. Ou seja, é o que buscamos, desejamos e nos completa de certa forma”. Já o entrevistado MMFRFCOP1112 define como: "É um conceito complexo, portanto científico. Ele requer ser estudado, investigado para que se tenha ciência sobre ele". Para ele é a sistematização de uma relação humana, especialmente para aqueles oriundos da áreas de Comunicação e Design. Ele lembra dela como um processo que tanto pode ser face a face ou mediado por um dispositivo tecnológico. Também concordando com a mesma premissa, o entrevistado MMERFINPU0912 enfatiza que é uma palavra plural, especialmente para designers de interação como o próprio se definiu. Ele reforça sua impressão, tendo em vista a relação do conceito de "interação" com alguns pontos de diálogo bem diferentes. Ou seja, pode ser um objeto de estudo para diversas áreas do conhecimento.

Agora sendo mais específico, outro entrevistado (identificado pelo código NMLCAGPU1112) trouxe uma nova dimensão para o entendimento do 
conceito de "Interação". Ele gosto de um conceito de "Interação" proveniente dos estudos do pesquisador Alex Primo (professor da UfRGs). Este docente e pesquisador não entende a interação por meio de uma visão reducionista, até simplicista, sem relacioná-la com a interatividade ou com produtos relativos com mídias interativas. Ele vê a interação como um reação e assim explica: "uma pessoa interagindo com uma máquina ou software terá uma resposta pré-programada, dentro de um seleção de alternativas existente no algoritmo daquela tecnologia. Por sua vez, o usuário irá responder de modo reativo - tal qual o artefato porém em outra dimensão. Então quando se fale em Interação Humano - Computador estamos lidando, de modo em geral, com esse tipo de interação". Todavia, também existe outro nível de "Interação", tida como mútua. Nela um humano pode interagir com outro ou, ainda, com diversos usuários - mas sempre mediado por uma máquina. Acima de tudo, dentro da mesma proposição, o entrevistado ressaltou que várias pessoas podem interagir entre si, onde todas participam ao mesmo tempo (contudo, respeitando a mesma dinâmica de mediação realizada pela tecnologia). Com isso, o interlocutor poderia habilitar mudanças, decerto alterações, durante o curso da própria "experiência". Para o colaborador, participante da pesquisa, isso significa um nível acima em termos "Interação". Por vezes, pode-se encontrar na interação mútua aspectos daquela denominada reativa, porém não é uma regra.

Para o colaborador MFCHMGPU1212 a "Interação" está ligada a forma com que ocorre o acesso ao conteúdo. Então, ele segue verbalizando: “...basicamente é responsável pela minha experiência de uso em um produto”. Depois o entrevistado segue: “...na interface é como eu irei 'tangibilizar' o que eu quero mostrar para a pessoa”.

Por sua vez, o colaborador mmebrgPu1212 entende o conceito de interação tal qual sua verbalização: "Você tem algum tipo de interface ou mecanismo, nele é a forma como a pessoa se comunica com aquele sistema. São também as repostas que o sistema produz para o usuário em função das ações que ele está executando. Também não é só uma interface, mas sim todo o ambiente - ou seja, o entrono que envolve aquele contexto. Por exemplo, uma tela que recebe o brilho de luz de uma luminária (seja atrapalhando ou beneficiando). Acho, principalmente que ele (usuário) interage, buscando um tipo de dado ou de informação. Com isso, os conceitos de informação e de interação estão relacionados".

Em busca de uma definição, ao menos com relação ao que se pode analisar até aqui, os participantes destacaram múltiplos aspectos relativos com a dimensão humana da "Interação". Também reconheceram um relacionamento, quase regulador, com um trinômio: tecnologia, tempo e informação. Assim, eles delimitam o entendimento sobre o conceito demandado para o tópico vigente. 


\subsection{Design de Interação}

No tópico atual, surgiram questões relativas com o projeto da experiência de diálogo em um contexto específico, tendo como meio ferramentas tecnológicas balizadas pelas competências dos indivíduos que operam sua interface. Nisso tudo, o entendimento holístico de como o usuário manipula, o que busca, o que o motiva e como prefere se comunicar com a tecnologia podem responder as questões propostas durante as entrevistas.

Com base no apresentado acima, o entrevistado MMERFINPU0912 por meio de uma abordagem mais ousada (segundo ele mesmo), especialmente quando cita os pesquisadores Sharp \& Rogers como sendo os seus preferidos. Já a partir deles, comenta a experiência como conceito mais contemporâneo. Ainda nessa visão, questiona sobre o que significa a interação como diálogo e como acontece o projeto nesse contexto. Em virtude disso, lembra o que seria sua referência anterior, tida como "Design de Interface", bem como seu aspecto limitador de desenhar telas estáticas. Nisso, cada uma não conversava com a outra, assim como ocorreu desde o surgimento da primeira interface gráfica. Nesse sentido, o entrevistado recorda a utilização de uma mesma metáfora, o "desktop" ou "mesa de trabalho", que influenciou o modo como se opera os sistemas de ícones, janelas, menus dominantes na maior parte dos aplicativos. No caso, o colaborador estava se referindo ao estilo de interação conhecido como Wimp (Windows, Icons, Menus, and Pointers). Ele segue seu raciocínio até o ponto em que julga o que seria a evolução: “...passa por pensar em um conjunto de telas com um único diálogo, onde passo a pensar no comportamento do usuário, nos gestos e na maneira com que ele interage com tudo isso. Nesse sentido, o ‘Design de Interação' contrapõe o ‘Design de Interfaces'. Ou seja, é um caminho para projetar diálogos. Como designer acredito que todo o produto interativo vem para resolver um problema de interação". Nesse sentido, o entrevistado defende o "Design de Interação" como um meio para se chegar as respostas de tais problemas.

De acordo com o colaborador MmLtPAPM1012 o "Design de Interação" tem o seguinte sentido: "É como eu projeto a interação. Mesmo que seja idealizada". Nesse ponto ele fala como designer, em primeira pessoa, como projetista e responsável por essa tarefa - quase como uma missão. Ele segue, ressaltando a faceta da "interação como projeto", excluindo o "acaso" de tal contexto, direcionando ela para um objetivo final, determinado a priori. Em seguida, o entrevistado buscou sintetizar o seu pensamento conforme segue: "É quando eu projeto a experiência que o cara vai ter em termos de interação". Enquanto para o entrevistado MMEBRGPU1212 é quando o profissional atua na forma de projetar a maneira como as pessoas irão interagir com o sistema. Aqui o colaborador fez referência ao sentido de materialização dos conceitos 
chaves do produto. Por isso, ele pensa no projeto de boas experiências de uso para qualquer tipo de sistema que, ao menos, que tenha um usuário no final da cadeia. Contudo, para isto ocorrer, o entrevisto defende que o designer tenha cuidado quando projetar ícones, símbolos, estrutura de navegação ou de acesso; enfim todos os elementos que compõem o design da tela e, depois, da interface. Também falando sobre experiência o entrevistado MFCHMGPU1212 versa sobre como o designer irá projetar a interação de um produto, em especial com que forma. Ele é responsável por fazer com que experiência interativa seja bem-sucedida, pois mesmo com as informações bem arrumadas ainda é possível que o usuário não alcance o que procura ou necessite fazer. Por isso, o colaborador defende uma relação muito próxima do "Design de Interação" com a "Arquitetura de Informação". Nesse mesmo caminho, o colaborador NMLCAGPU1112, destaca que o "Design de Interação" deveria dizer respeito ao ato de projetar um determinado produto que irá desempenhar o papel de mediação entre os diversos tipos de interação possíveis - a saber, já recordando, seja a reativa ou a mútua. Ele segue, remetendo o conceito ao desenho, o estudo e a busca relativa com a previsão de como as interações irão ocorrer. Enquanto, o participante DMLMACOP1112 traz um entendimento mais instrumental e tecnológico sobre o "Design de Interação". Assim, para ele (ao defender seu ponto de vista) formula e cita: "Fazer projetos que usem todas as capacidades multimodais das ferramentas".

Nesse ponto, ele lembra dos exemplos dos consoles e os dispositivos com "touch". Com isso, acredita na diversão como parte da equação conceitual que busca definir o "Design de Interação", decerto crê que esse estilo de interação mais natural visa explorar toda a potencialidade da "seleção direta" da informação. Para isso acontecer, ele remete ao design, no sentido de projeto, fazendo com que as pessoas usem as tecnologias de modo natural - sem parecer que necessitam de grande esforço e, sobretudo, faça sentido (principalmente) no momento do uso. Desse modo, ele afirma: "Fazer um coisa que faça sentido naquele momento e não por meio gratuito da tecnologia. O grande lance é ter sentido". Para explicar melhor o seu pensamento o entrevistado continua: “...não o uso gratuito da tecnologia. A gente vê quando alguma coisa é forçada e quando outra é natural. Assim, ela se fecha, encaixa e existe um envolvimento verdadeiro". Com o objetivo de concluir seu entendimento ele diz: "... o quanto as pessoas se apropriam, aproveitam e deleitam sobre essa integração delas com a informação por meio da interface"

Para o profissional e educador MMFRFCOP1112, propõe uma abordagem similar quanto a relação entre áreas de conhecimento, mas busca hierarquizar essa relação. Desse modo, ele postula que o "Design de Interação" é um nível ulterior ao "Dado", a "Informação" e a "Arquitetura da Informação", pois essa 
área se vale dos anteriores, dependendo deles como sustentação. Com isso, parece macro contendo os demais. Em seguida, o entrevistado retorna para o enfoque da sistematização das relações mediadas como forma de resolver problemas tipicamente humanos. Ele encerra suas considerações sobre "Design de Interação", destacando sobre a sua importância como disciplina moderna, atual e contemporânea, onde suas bases não estão fundadas em uma única área de conhecimento. Ela está além da interdisciplinaridade, uma vez que articula todos os conceitos com o intuito de projetar soluções por meio do "Design" em especial, quando a interação é um problema, mas faz uso de outras abordagens. Por conseguinte, pode-se entender o "Design" aqui como projeto, visão e perspectiva na forma materializada de um artefato digital interativo.

Como encerramento, somente do tópico em questão, sem fazer relações amplas com o restante do documento de pesquisa e após o que fora relatado pode-se entender que o conceito de "Design de Interação" versa sobre espaços tecnológicos de comunicação por meio de uma interface natural, de cunho gráfico, onde o projeto visa que os usuários manipulem o produto informacional de modo pleno, tal qual ele fora concebido na "mente" dos desenvolvedores.

\subsection{Arquitetura de Informação}

As considerações feitas sobre o conceito de Arquitetura de Informação passaram por assuntos relativos com o excesso de informação e a contribuição da disciplina para tal dilema. Ademais, as abordagens orientadas para o sistema ou o usuário também foram citadas, bem como outros relacionamentos com "empoderamento" da pessoa mediante ao se transformar o complexo em simples e a proximidade dela com o "Design de Interação". Com isso, o fluxo da informação e todas as estruturas de acesso - mesmo que sejam multiplataformas ou "cross-media" - com o usuário são tópicos relevantes que foram citados ao longo das entrevistas.

A abordagem inicial feita por um dos primeiros entrevistados, o colaborador de código mmLtPapm1012, busca definir "Arquitetura de Informação" de maneira íntima e projetual, pois para ele: "...é como eu desenho a estrutura da informação, faço a construção informacional...”. O designer e professor, de código MMERFINPU0912, tem uma visão conceitual da "Arquitetura de Informação" quando comparada com o "Design de Interação". Para ele, em virtude da massa de informação (usualmente complexa) é necessário organizá-la com intuito dela ter sentido para as pessoas. O educador e designer (DMLMACop1112) defende que a Arquitetura de Informação, seja ainda, mais importante em produtos (p.ex.: sites, intranets e revistas digitais) com uma vasta quantidade de informações. Por meio dessa ótica, o entrevistado segue com uma pergunta: "Como você faz essa grande quantidade de informação ficar palatável para o 
usuário?". Para isso, o participante MMERFINPU0912 sugere dos sentidos, recordando o trabalho de Morville (de modo mais recente e atual): o primeiro seria com o enfoque humano (abordagem bottom-up) por meio de vocabulário controlado, de taxinomia adequada e de sistemas de navegação projetos segundos à ótica dos usuários. Enquanto o segundo, provém da máquina para a pessoa (abordagem top-down). Desse modo, deve também fazer sentido para o sistema, criando a facilidade da máquina entender a informação. Por conseguinte, pode-se chegar em novas formas de Interação Humano-Tecnologia, seja por meio da "Web Semântica", de sistemas de buscas com algoritmos poderosos e de robôs de rastreamento cada vez mais eficientes. De modo similar, também colaborando, o docente e profissional MMERFINPU0912, ainda lembra que esta disciplina é um sinônimo para criação de rotas, visando facilitar o acesso aos ambientes ou sistemas de informação. Nessa mesma linha de pensamento, ele volta para Wurman destacando a proposição feita pelo pesquisador ao relacionar a A.I. com o "Design de Informação", quase como se o segundo fosse uma atualização do primeiro conceito, onde a meta idealizada está em gerar "empowerment" no usuário ao transformar a informação complexa em simples. Enquanto para o designer e professor (ммLтрарм1012), em especial, a disciplina versa sobre como é feito o projeto do acesso, da organização e do condicionamento da própria informação. Além disso, o repositório dela está contido em seu entendimento e, de modo surpreendente, o entrevistado relaciona a Arquitetura de Informação com a estética, mas logo em seguida considera que ela envolve cálculo. De qualquer modo, entre os tópicos da entrevista o colaborador exemplifica, postulando que a beleza está na simplicidade como um físico ou matemático tanto resolvem como propõe uma fórmula. Assim, talvez, em parte ele tenha se referido ao desenho conceitual de uma estrutura, da definição da taxonomia e das estratégias tanto de recuperação como uso da informação em uma estrutura quase natural, invisível, minimalista - porém, simples e eficiente. Em outra entrevista, a "Arquitetura de Informação" para o colaborador MMFRFCOP1112 foi definida em primeira instância como um campo de aplicação, em especial, versando sobre uma lógica e coerência estrutural (quase arquitetônica) sobre a organização e sistematização da informação em um dado contexto.

Para o colaborador NMLCAGPU1112 a "Arquitetura de Informação" é uma prática profissional que busca adequar, estruturar, desenhar e construir a informação que vai ser apresentada ou consumida por alguém. É um campo de trabalho bastante abrangente que envolve vários agentes ou especialistas, sendo de cunho técnico e aplicado.

O participante MFCHMGPU1212 contribui com o debate conceitual iniciado aqui ao afirmar que a "Arquitetura de Informação" não sobrevive sem o 
"Design de Interação". Para justificar seu ponto de vista ele busca estabelecer diferenças entre as áreas, por meio do perfil profissional, onde o "arquiteto" tem maior habilidade para lidar com "a estrutura", concebendo a experiência de modo sistemático. Enquanto o "designer" trabalha com "o visual”, ou seja como se relaciona a interação com a experiência. Desse modo, o entrevistado segue defendendo um proposta mais moderna para a primeira área (citada no início de sua argumentação). Com isso, ele contrapõe Rosenfeld e Morville autores da obra "Information Architecture for the World Wide Web" - com sua visão clássica da A.I., onde a ótica está no fluxo, no "wireframe", no rótulo e no sistema de busca; enfim na navegação. Para o colaborador a "Arquitetura de Informação", em uma visão contemporânea, também deve lidar com os dados por meio do sistema que irão entregar a informação para o usuário. Assim, surge outra demanda, em conjunto com o designer de interação, de como se pode organizar a informação na tela (de modo prioritário), indo além da visão clássica. Nesse sentindo, fazendo com que a experiência faça parte do projeto. Em especial, em uma visão centrada no usuário.

O entrevistado citado no parágrafo anterior, de modo surpreendente, frisou que só é possível saber o que "Arquitetura de Informação" quando se trabalha com ela. Nesse sentido, ele busca exemplificar relacionando a função do "arquiteto" com o produtor de um filme, pois ele seria o responsável pela escolha do elenco e da locação para as cenas. Já o diretor seria o "designer de interação" com a responsabilidade de passar a visão do projeto. Mesmo que questionável em sentido, esta analogia vale para demonstrar a relação quase simbiótica proposta pelo colaborador entre as duas áreas. Ademais, o entrevistado, desde o início, sempre buscou destacar a relação dessas áreas com a atividade prática quase como se o ofício retroalimentasse as pesquisas e o pensamento mais conceitual em um ciclo infinito.

Segundo o participante MmeBrgPu1212 a "Arquitetura de Informação" é uma atividade relacionada com o projeto. Ela tem um interface muito grande com o "Design de Interação". Sendo assim, para o entrevistado é muito complicado, por vezes, separar as duas disciplinas. Isto ocorre, devido ao sentido de complementariedade existente entre ambas. Sobre a "Arquitetura de Informação", o entrevistado defende que a sua definição deve ir além da função clássica. Assim sendo, hoje além do projeto de navegação a A.I. é uma atividade voltada para melhorar processos ou fluxos relacionados com:

1. Rotinas dentro do sistema (projeto de funcionalidades, diagrama de navegação, otimização de fluxos, avaliação da interface e documentação do produto). 
2. Comunicação do usuário com o sistema (tecnologia informacional em geral).

3. Áreas diferentes de uma mesma corporação.

4. Sinalização da informação no cotidiano das pessoas.

De modo, bem específico, ele sugere que a atividade do arquiteto de informação passa por projetar funcionalidade de um sistema. A AI pode ser uma atividade estratégica para empresa, pensando o produto por esse olhar inovador. Assim, por meio dessa atitude sobre os requisitos e as funcionalidades de um produto pode-se chegar a uma vantagem competitiva e, como isso, consegue-se traduzir todo o processo em benefício direto para a corporação, seja por meio do desenvolvimento de um diferencial alcançado quando comparado o artefato com os seus concorrentes. $\mathrm{O}$ entrevistado formula, em virtude dessa mudança, uma proposição sobre o avanço da disciplina (para ele representou um retrocesso), pois em 1976 (logo que a AI foi difundida) podia-se dizer que ela surgiu para melhorar a compreensão dos dados, melhor dizendo, de informações bidimensionais existentes prioritariamente em mapas e infográficos, mas hoje essa essência foi perdida ficando (somente) o enfoque digital relativo com as técnicas de produção (lista de conteúdos, mapas de navegação, fluxogramas e documentação em geral).

\subsection{Competências relativas com os perfis}

O tópico sobre as competências relativas com os perfis profissionais relativos com a "Arquiteto de Informação" e o "Design de Interação" representou um desafio para os colaboradores do estudo, mas trouxe interessantes observações sobre o como o mercado demanda e, ao mesmo tempo, enxerga essas atividades. Assim, de início, os entrevistados consideraram que as competências são muitas, decerto diversas, diferentes e talvez complementares em alguns momentos. Por isso, tratam-se de aspectos transdisciplinares, ou seja o profissional deve ter inúmeras valências de áreas de formação distintas. Contudo, de maneira geral, ainda pode-se encontrar interseções dentre as macro - competências. Dito isso, seguem na sequência algumas citadas ao longo das entrevistas. Dentre elas estão: a pesquisa, a representação (configuração), a análise e o trabalho colaborativo (no caso, em equipe). Ademais, elas também podem se desdobrar em: conhecimento (relativo com definições, tipologia e classificação), habilidade para lidar com o volume de informações, bem como o processo delas por meio de software. Aqui, tem-se sempre uma atitude investigativa de maneira transversal as demais competências. Em conjunto com o proposto, como adjetivos inerentes para tais profissionais, ainda vale mencionar: 
pensamento funcional em conjunto com aquele descrito como objetivo, interesse por tecnologia e capacidade de argumentação (defesa de ideias em equipes multidisciplinares). De qualquer modo, apesar da síntese apresentada, o entrevistado DMLMACOP1112 elenca a "curiosidade" como sendo uma atitude chave, quase uma habilidade na opinião dele, para os profissionais envolvidos com "Arquitetura de Informação" e "Designer de Interação". Ele considera que deveria ser uma atitude para o restante da "jornada profissional" de qualquer indivíduo, principalmente daqueles oriundos de uma atividade tecnológica ou de qualquer outra que sofra impacto dela.

Já o mercado (de modo abrangente) para os entrevistados, busca por profissionais que tenham um a visão clara e bem definida de suas atribuições/ funções. Em primeira instância para a área, tendo como segundo nível (em um caráter subsequente) as demandas implícitas no próprio projeto. Assim, devido a complexidade com que os produtos interativos alcançaram, por vezes a especificidade faz parte da competência necessária. Desse modo, a necessidade de contratação passa pela características contidas na fase atual do desenvolvimento. Além disso, o perfil do profissional desejado deve complementar as competência existentes na equipe (técnicas, emocionais, psicológicas e sociais). Para alguns dos entrevistados o perfil do arquiteto de informação pode ser mais amplo do que do designer de interação, já que para algumas empresas a demanda da coordenação colaborativa recaí sobre ele.

Se o indivíduo se coloca em atividade essencialmente prática com o objetivo de encontrar soluções, parece que ser autodidata configuraria o melhor caminho para aqueles iniciados nessas carreiras. Em conjunto com isso surge a prática, tendo em vista, que é o melhor posição para se encontrar soluções. Desse modo, a experiência profissional e a percepação de como o "mercado caminha" permitem que o indivíduo se reinvente - tal qual o pensador Domenico Dimase já previa. Por meio de uma proposta similar, o entrevistado MMFRFCOP1112 relaciona competência profissional com a obra de Pierre Rolle ao destacar "saber fazer e ser". Para ele a primeira parte diz respeito com as questões que delimitem - ao mesmo que tempo que definem o campo profissional em questão, seja especialmente pelos seus conceitos e termos. Enquanto "o fazer" dignifica a prática pela experiência, aprendendo a ser um "Arquiteto da Informação" ou "Designer de Interação". Nesse ponto, ele considera que a AI é uma disciplina anterior, em especial pela sua relação mais próxima com o desenvolvimento histórico da Internet. No entanto, ele afirma que a academia é a grande formadora desses perfis, em especial a partir dos cursos de pós-graduação, pois a formação superior não dá conta - de modo pleno - dessas novas áreas. Ainda para educador entrevistado, os programas de Mestrado e de Doutorado são responsáveis por levar essas áreas para outros níveis. Ainda 
colaborando com este posicionamento, o entrevistado MMEBRGPU1212 afirma que não existe uma formação básica específica (graduação tecnológica ou bacharelado) que prepare esses profissionais (isto só acontece dos cursos de especialização em diante conforme já fora dito), porém defende algumas características importantes: ser curioso, detalhista, trabalhar de modo colaborativo, ter uma visão mais holística do projeto, ser flexível (líder com as diversas variáveis do projeto - custo, prazo e etc.), gostar de estudar e da área em si.

De maneira, ainda mais atual, a demanda por relações passa necessariamente pela mediação cada vez mais presente. Assim, decerto a questão que surge para o profissional de "Design de Interação" é saber como as pessoas se comportam quando se relacionam com esses dispositivos tecnológicos. E mais, como um usuário ou mais tentam acessar essas informações e, de que maneira, elas se comportam nesse processo comunicativo. Além disso, para o entrevistado MmFrFCop1112 parece ser uma questão de "olhar". Dito isso, busca encerra sua argumentação (com uma missão profissional), remetendo a experiência em si. Desse modo, ele diz: "é lidar com questões que implicam em como as informações úteis estão sendo acessadas ,recuperadas e utilizadas. Assim, tem existir um outro olhar! É uma competência técnica, melhor tecnológica. Quais são as tecnologias? O que eles te permitem fazer? Como elas podem viabilizar uma séria de relações comunicativas? E ainda, tem um terceiro aspecto, tido competência projetual. Acho que é a mesma competência que um 'Arquiteto' ou um ‘Engenheiro' tem , o ‘Designer' também deveria possuir. De ver o processo em cadeia”. De modo mais prático, o profissional e educador (identificado pelo código MMERFINPU0912) lembra que a bagagem e os produtos criados ou testados podem indicar (quando se tem o acesso sobre o impacto dele na população usuária) uma competência derradeira, bem como definitiva sobre a percepção de qualidade de uso. Com isso, a competência do profissional seria perceptível (quase certificada e palpável).

Com base no entendimento proposto até aqui, parece seguro supor que a formação do profissional é um "área cinza" tal qual o entrevistado MMERFINPU0912 expressou em seu discurso. De acordo com ele não existe um curso que contemple todas as competências para formação desses profissionais no Brasil - relacionados com a "Arquitetura de Informação" e "Design de Interação". Mesmo que seja concebido individualmente para cada uma das áreas. Já o colaborador NMLCAGPU1112 entende que as competências para formação do "arquiteto da informação" e do "designer de interação" podem ser dividas em mercado internacional e brasileiro. Para o primeiro recorte deve existir tamanha especificidade, de modo que as áreas sejam separadas em termos de competências e cursos de formação. Já no caso do Brasil, o entrevistado defende uma formação conjunta. Ademais, ele enfatiza que a "Arquitetura 
de Informação" deve conter, de modo prioritário, competências oriundas da Ciência da Informação. De modo complementar, outras áreas como o Design e Comunicação também seriam relevantes para formação desse profissional. No caso do "Design de Interação" a essência está no Design (seja Gráfico ou de Produto) e, de modo subsequente, no Desenvolvimento de Software e nas Ciências Sociais (prioritariamente economia e sociologia). Para ele o marketing seria importante para as duas formações.

De acordo com o entrevistado mMEBRGPU1212, agora tecendo considerações sobre competências comuns para os profissionais em debate segue, postulando uma competência macro para as duas disciplinas - "Design de Interação" e "Arquitetura de Informação". Dito isso, ele comenta o desenvolvimento de projetos centrados no usuário, em especial no modelo mental daquela pessoa (usuário final). Em virtude disso, especialmente por conta do modo de interagir ser muito particular - quase próprio - deve-se estudar como as pessoas manipulam a interface. Por meio de uma argumentação toda sua, tipicamente íntima, ele também defende que esses profissionais devam ser humildes - no sentido de apreenderem a escutar as pessoas envolvidas no projeto (desde os colaboradores, os parceiros de equipe até os usuários).

O participante MFCHMGPU1212 continua, só que no momento, enfatizando algumas distinções a partir do reconhecimento das similaridades existentes. Com isso, apesar do "arquiteto de informação" e "designer de interação" trabalharem juntos existe uma diferença clara entre eles. O primeiro começa organizando como o produto vai funcionar, desde verificação dos dados disponíveis até o modo como as informações serão organizadas e hierarquizadas na tela. Já o segundo visa "estática funcional" ou como desenho da interface se relaciona com a interação. No caso, estão contidas a visão de design gráfico mais básico (hierarquia, peso, contraste e etc.), o comportamento humano, o projeto tipográfico, o Marketing e, principalmente, o pensamento de produto (o que se deseja com o ele, para quem se fala, onde se quer chegar, como ele melhora a experiência e como se alcança a parte emocional da audiência). O participante segue e elabora outro nível quando diz: "Não adiante ser lindo e funcional, se não tem uma mensagem clara de conteúdo".

\section{Conclusão}

Como resultante, de tudo que fora relatado aqui, parece seguro afirmar que o mapeamento da carreira segue por pesquisa, atitude crítica e afeição pela própria atividade. Além disso, a percepção do aprendizado deve ser contínua, seja por um necessidade de informação, pelo anseio de dominar competências 
emergentes ou, sobretudo, por ter um entendimento claro do que o mercado está demandando. Assim, por fim, as competências descritas aqui (relativas com o mapeamento citado) devem ser revistas sempre que possível, pois têm caráter temporal e refletem o contexto estudado neste documento.

Por fim, aproveitando os conteúdos oriundos das entrevistas, deve-se entender o ser humano antes de se estabelecer qualquer metodologia de projeto. Após o que fora relatado, chega-se (em síntese) ao entendimento que as etapas de produção seguem ciclos curtos que vão se alimentando, em um espiral ascendente, que passam de fases conceituais (no início) até outras mais palpáveis com a imagem do produto finalizado. Em seguida, testes de qualidade de software e outras relativos com o feedback da audiência (quando o produto já está publicado) refinam o artefato para o seu lançamento. No entanto, cabe assegurar que os testes com usuários sejam uma tônica por todas as fases, sempre mantendo cuidado para que cada fase tenha as informações necessárias que permitam passar para outras etapas em ciclos evolutivos. Por fim, o processo deve ser ágil e flexível, tendo sempre fases de design de interface relacionadas com fatores de branding, de viabilidade de mercado, de revisão de funcionalidades de "Design Interação" e de "Arquitetura de Informação". E finalmente, de modo ideal/conceitual chega-se a experiência perfeita para aquele usuário final típico, onde a Tic se torna uma extensão do ser humano.

\section{Referências Bibliográficas}

FLEMING, J. Web Navigation: Designing the User Experience. Sebastopol: Richard Koman Editor, 1998.

GARRETT, J. J. The elements of user experience. New York: AIGA, 2003.

JORDAN, P.W. Foreword. In: BLYTHE, M. A., OVERBEEKE, K., MONK, A. F., WRIGHT, P. C. Funology: from usability to enjoyment. London: Kluwer Academic Publishers, p. 11, 2004.

MACEDO, F. L. O. Arquitetura da informação: aspectos epistemológicos, científicos e práticos. Dissertação (Mestrado em Ciência da Informação) Universidade de Brasília. Brasília, p. $186,2005$.

PREECE, J., ROGERS, Y. \& SHARP, H. Interaction design: beyond human-computer interaction. New York: John Wiley \& Sons, Inc., 519p., 2002. 
SAFFER, D. Designing for interaction: creating smart applications and clever devices. Berkeley: New Riders, 231p., 2007. 
Recebido em: 10/06/2013

Aceito em: 01/10/2013

\section{Como citar}

TEIXEIRA, Eduardo Ariel de Souza. A interação em estudo: as análises das correntes teóricas sobre o conceito de design de interação para profissionais e educadores. Arcos Design. Rio de Janeiro: PPD ESDI - UERJ. Volume 7 Número 2 Dezembro 2013. pp. 1-24. Disponível em: [http://www.e-publicacoes.uerj.br/ index.php/arcosdesign]

\section{DOI}

10.12957/arcosdesign.2013.12179

\section{c) (1) (2)}

A Revista Arcos Design está licenciada sob uma licença Creative Commons Atribuição - Não Comercial - Compartilha Igual 3.0 Não Adaptada. 